\title{
Criança e luto: vivências fantasmáticas diante da morte do genitor ${ }^{1}$
}

\section{Children and grief: fantasies about a parent's death}

\author{
Maria Helena Pereira FRANCO ${ }^{2}$ \\ Luciana MAZORRA ${ }^{2}$
}

\begin{abstract}
Resumo
Este estudo clínico qualitativo objetivou investigar fantasias da criança enlutada pela morte de um ou ambos os pais e sua relação com o processo de elaboração do luto. Foram realizados estudos de caso com meninos e meninas, de três a oito anos de idade, enlutados em decorrência da morte de um ou ambos os genitores, indicados para atendimento psicoterápico em uma clínica-escola. Como instrumentos de investigação, foram utilizadas entrevistas com o genitor sobrevivente ou responsável pela criança, uma entrevista familiar, três entrevistas lúdicas e a aplicação do procedimento de desenhos-estórias com a criança. Apreenderam-se fantasias de aniquilamento, culpa, castração, onipotência, rejeição, identificação, retaliação, idealização e desidealização do objeto perdido; agressividade; negação da perda; regressão; reparação; repetição da situação da perda. Foram apontados sentimentos, comportamentos e sintomas por meio dos quais as fantasias foram expressas. A construção das fantasias mostrou-se relacionada ao desenvolvimento psicossexual e cognitivo e ao modo de funcionamento egóico da criança, condições circundantes ao evento da morte e dinâmica familiar. Entre esses fatores, apontaram-se os facilitadores e os dificultadores da elaboração do luto. Percebeu-se que as fantasias refletem o processo do luto e seu conhecimento possibilita a compreensão de seus sentimentos, comportamentos e sintomas e que estão associadas a processos elaborativos do luto.
\end{abstract}

Unitermos: criança; fantasia; luto; morte.

\begin{abstract}
This clinical psychoanalytical qualitative study aimed to investigate the fantasies of bereaved children - due to the death of one or both of the parents - and the way thesefantasies act in the grief process. Five case-studies were carried out, with boys and girls, from three to five years old, bereaved due to death of father and/or mother, who had been referred to psychotherapy. As investigation resource, interviews were made with the survivor parent or person responsible for the child, a family interview, play sessions with the child and the Drawing-Story Test. The fantasies that were identified were: Annihilation; Guilt; Castration; Omnipotence; Rejection; Retaliation, Idealization and non-idealization of lost object, Aggressiveness; Identification with lost object, Denial of loss, Regression; Reparation and Repetition of the loss situation. There were also indicated feelings, behaviors and symptoms, by the expression of fantasies. The construction of these fantasies was related to: psychosexual and cognitive development stage, ego functioning, surrounding conditions related to the death and family dynamics. Among these factors, those that facilitate or jeopardize the grief process were identified. The fantasies reflect the process of grief work and their awareness allows the feelings, behaviors and symptoms understanding and they are associated to the grief processes. .
\end{abstract}

Uniterms: child; fantasy; grief; death.

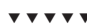

1 Artigo elaborado a partir da dissertação de L. MAZORRA, intitulada"A criança e luto: vivências fantasmáticas diante da morte do genitor". Pontifícia Universidade Católica de São Paulo, 2001, com apoio da Fapesp.

2 Pontifícia Universidade Católica de São Paulo, Programa de Estudos Pós-Graduados em Psicologia Clínica, Laboratório de Estudos e Intervenções sobre o Luto. R. Ministro Godoy, 969, $4^{\circ}$ andar, Sala 4E5, 05015-901, São Paulo, SP, Brasil. Correspondência para/Correspondence to: M.H.P. FRANCO. E-mail: <mhfranco@pucsp.br>. 
A morte de um genitor é uma das experiências mais impactantes que a criança pode vivenciar. Com os pais, morre também a ilusão narcísica da onipotência infantil em um momento em que ela é necessária como fonte de segurança. Diante da ausência irreversível de um vínculo provedor de sustentação, a criança se depara com profundos sentimentos de desamparo e impotência.

Com a morte de um genitor, a criança perde o mundo que conhecia, aquele em que o genitor podia afastar-se e ao qual retornava. Agora seu mundo está enlutado: torna-se difícil lidar com toda a gama de sentimentos que parecem invadi-la com o desmoronamento da família. O luto é o processo de reconstrução, de reorganização, diante da morte, desafio emocional e cognitivo com o qual ela tem de lidar.

O atendimento de crianças enlutadas pela morte de um ou ambos os pais suscitou-nos o interesse de estudar as fantasias que permeiam seu imaginário, ou seja, como tal situação se inscreve no mundo fantasmático dessa criança, refletindo seu processo de luto. A importância de estudar as fantasias de crianças que perderam um ou ambos os pais diz respeito à concepção psicanalítica de que o sintoma, presente no processo de enlutamento, é a expressão simbólica de construções fantasmáticas (Freud \& Breuer, 1893 - 1895 [1996]). Além disso, a fantasia é a representação de desejos, disfarçados em maior ou menor grau por processos defensivos; é a satisfação de um desejo insatisfeito, a correção de uma realidade não satisfatória. Portanto por meio das fantasias seria possível apreender a dinâmica do luto, tendo-se em conta os sentimentos, reações e sintomas envolvidos e o modo como a criança processa a realidade concreta da perda de um ou ambos os pais.

A literatura encontrada sobre o processo de luto da criança em sua grande parte é estrangeira (Beckman, 1990; Guérin, 1979; Sekaer, 1987; Worden, 1996) e descreve as reações e sintomas que podem ser apresentados pela criança de faixas etárias diversas que vivencia diferentes tipos de perda. No entanto pouco é encontrado a respeito dos mecanismos intrapsíquicos envolvidos na elaboração do luto da criança.

5043 Phantasie, em Alemão

\section{Fantasia}

Na Psicanálise, de acordo com Laplanche e Pontalis (2000), fantasia ${ }^{3}$ refere-se ao mundo imaginário, a seus conteúdos e à atividade criadora que o anima. Já o termo francês fantasme, colocado em uso pela psicanálise francesa, designa determinada formação imaginária, mas não a atividade imaginativa em geral. Os autores definem essa formação imaginária como um roteiro imaginário do qual o sujeito faz parte, que representa a realização de um desejo de modo mais ou menos deformado pelos processos defensivos. Em sua revisão sobre o conceito de fantasia dentro da obra freudiana, apontam que no que se refere à situação tópica, Freud não realiza uma distinção de natureza entre fantasia inconsciente e fantasia consciente, mas, diversamente, busca as ligações existentes entre ambas.

No presente trabalho, compreendemos as fantasias como as formações imaginárias do sujeito que representam a realização de desejos. Não pretendemos distinguir fantasias conscientes e inconscientes, tendo em vista a estreita ligação existente entre ambas. Compreendemos também a fantasia como um fenômeno construído de acordo com a realidade psíquica do sujeito que a constrói, numa interação constante com o mundo externo e interno. Dessa forma, pensamos que a experiência concreta de morte de um ou ambos os pais está relacionada à constituição das fantasias da criança.

\section{Luto na infância}

Freud, em Luto e Melancolia (1917 [1915] [1996]), descreve o luto como um trabalho que o ego tem de realizar para adaptar-se à perda do objeto amado, perante a percepção propiciada pelo teste de realidade de que esse foi perdido. A elaboração do luto foi descrita na teoria psicanalítica como um processo de identificação com o objeto perdido, no qual há retirada gradual do investimento libidinal nesse objeto e investimento libidinal em novos objetos. Esse processo não implica o desligamento total do objeto perdido, tendo em vista que a ligação com o objeto interno permanece e é ressignificada durante o trabalho de luto. É esse 
trabalho de ressignificação, de transformação da relação com o objeto perdido, que permite a elaboração do luto.

Como bem apontam Laplanche e Pontalis (2000), o conceito de trabalho de luto é bastante inovador na compreensão do enlutamento. Anteriormente visto, especialmente pelo senso comum, como uma atenuação espontânea e progressiva da dor desencadeada pela perda de um ente querido, é descrito por Freud como um processo elaborativo que depende da atividade do sujeito e pode ser ou não bem-sucedido. É uma forma de elaboração psíquica que consiste na ligação no aparelho psíquico de impressões traumatizantes, integração de excitações e estabelecimento de conexões associativas entre elas.

Bowlby $(1960,1993)$ define pesar como a aflição experimentada pela pessoa que perde um ente significativo e a seqüência de estados subjetivos que acompanham o enlutamento. O luto é considerado o trabalho psíquico de elaboração dessa perda.

Enquanto a criança não pode reconhecer seus objetos de amor como sendo separados dela, na eventualidade da perda ou separação da mãe, ela sente que perdeu uma parte de si própria, mas não pode sentir pesar e enlutar-se pelo objeto amado. Tendo em conta as contribuições de Klein (1970,1996a, 1996b), Bowlby (1960,1993) e Winnicott (2000), autores de diferentes escolas psicanalíticas que estudaram o tema do luto na infância, podemos pensar que entre quatro e sete meses de idade, aproximadamente, a criança sente pesar e fica enlutada na ocasião de uma perda ou separação de uma figura significativa. Embora sua capacidade simbólica seja limitada, haveria já o desenvolvimento primitivo de processos psíquicos de elaboração.

Para Bowlby (1993), a partir de dezesseis meses de idade, aproximadamente, a criança teria mais recursos cognitivos e emocionais para elaborar o luto como o adulto. Consideramos arriscado, no entanto, comparar esse incremento de recursos emocionais da criança dessa idade com a capacidade elaborativa do adulto, uma vez que o psiquismo da criança está em formação.

Do ponto de vista dos recursos cognitivos da criança, Torres (1999), tendo em vista os estudos de Piaget, aponta que a criança somente compreende a irreversibilidade da morte quando atinge o modo de pensamento Operatório Concreto, por volta dos sete anos de idade. A maior dificuldade de compreender a irreversibilidade da morte pode dificultar o processo de elaboração da perda.

Segundo Scalozub (1998), toda criança tem dificuldade de elaborar a perda de um objeto amado, principalmente aquele do qual depende, pois seu psiquismo ainda está em desenvolvimento, e ela necessita das pessoas que garantem sua sobrevivência física e desenvolvimento emocional.

Em função de sua maior dificuldade cognitiva e emocional para significar a perda, a elaboração do luto vivido pela criança é processada ao longo da estruturação psíquica, em distintos momentos de sua vida, à medida que ela vai podendo significar o que viveu. 0 luto pode ser reativado, também, ao longo da vida, ao encontrar ressonância com conflitos do futuro desenvolvimento. Isso não compreenderia patologia, um luto adiado, mas sim sua elaboração, já que nenhum trauma na infância pode ser resolvido até que a criança cresça (Sekaer, 1987; Scalozub, 1998; Worden, 1998).

Portanto as crianças elaboram o luto; porém têm um modelo próprio de elaboração, sendo equivocado impor-Ihes o modelo adulto. Seu luto não é uma versão deficiente do luto do adulto. Tem características específicas, haja vista que a criança está em processo de estruturação de sua personalidade (Sekaer, 1987; Worden, 1998).

O modo como a criança é capaz de elaborar a perda de um ente querido relaciona-se a fatores intrapsíquicos (elaboração da posição depressiva arcaica e recursos para elaborar perdas) e fatores externos (relação com a pessoa perdida; relação com o pai sobrevivente; circunstâncias em que a perda ocorreu; informação recebida pela criança; possibilidade de comunicação sobre o que aconteceu e sobre a pessoa perdida; dinâmica familiar; tipo de morte; rituais; estressores e mudanças no cotidiano da criança) e está em estreita relação com a possibilidade de elaboração do genitor sobrevivente e do restante da família (Aberastury, 1973; Bowlby, 1993; Domingos \& Maluf, 2003; Guérin, 1979; Klein, 1996a; Kraus \& Monroe, 2005; Nickman \&Normand, 1998; Winnicott, 1994; Worden, 1996).

A presente pesquisa teve por objetivo investigar o universo de fantasias da criança enlutada pela morte 
de um ou ambos os pais, para averiguar como tal perda atua sobre o mundo fantasmático da criança, e de que modo suas fantasias se relacionam com seu processo de elaboração do luto.

\section{Método}

Trata-se de uma pesquisa qualitativa clínica, realizada por meio de estudos de caso, baseada em um referencial teórico psicanalítico.

\section{Procedimentos}

Cinco crianças de ambos os sexos, de três a oito anos, enlutadas pela morte de um ou ambos os pais, ocorrida no máximo um ano antes da pesquisa, e seus responsáveis, que procuraram atendimento psicoterápico oferecido pelo Laboratório de Estudos e Intervenções sobre o Luto (LELu), da Pontifícia Universidade Católica de São Paulo (PUC-SP), sob seu consentimento 4 .

Optou-se pela seleção de crianças que estavam enlutadas até um ano antes da pesquisa porque em nossa experiência clínica percebemos que esse seria usualmente o momento em que o luto estaria mais agudo e as fantasias relacionadas à morte mais vivas e freqüentes.

A coleta de dados foi realizada na Clínica Psicológica "Ana Maria Poppovic", da PUC-SP.

\section{Instrumentos}

\section{Entrevistas clínicas}

Entrevista com o genitor sobrevivente ou responsável: primeiramente foi realizada uma entrevista semidiretiva com o pai, a mãe ou o responsável pela criança. Nas entrevistas foi utilizado um roteiro de questões realizado e aplicado por uma das pesquisadoras em seu trabalho de conclusão do curso de Psicologia na PUC-SP (Mazorra, 1997). Os principais fatores investigados foram relatos ou observações sobre:
- Características da criança: idade, sexo, desenvolvimento anterior e posterior à perda;

- Processo de luto da criança: seu comportamento; presença de sintomatologia característica do processo de luto (tristeza, choro, retraimento, inibição psicomotora, agressividade, alteração de apetite, alteração do sono);

- Dinâmica familiar antes da morte;

- Relação da criança com o falecido;

- Dinâmica familiar posterior à morte: cuidado do (a) pai/mãe sobrevivente ou de um substituto; possibilidade de participar do luto familiar e expressar seus sentimentos;

- Fantasias expressas da criança a respeito da morte;

- Fornecimento de informação para a criança sobre o que aconteceu e existência de oportunidade para fazer perguntas.

Entrevista familiar: nesta entrevista o profissional oferece uma caixa com material gráfico e lúdico e observa a família em interação (Arzeno, 2003). Além dos fatores investigados na entrevista com o genitor sobrevivente ou responsável, procurou-se apreender: a dinâmica da família por meio de sua observação direta e da transferência estabelecida com a pesquisadora; fantasias compartilhadas pela família.

Entrevistas lúdicas: a entrevista lúdica é uma técnica de investigação clínica da personalidade da criança introduzida inicialmente por Aberastury (1992). Nesse procedimento, o comportamento da criança é observado em uma sala destinada à ludoterapia, com brinquedos e material gráfico (Trinca, 1983). Tendo em vista que a atividade lúdica é a forma como a criança expressa suas fantasias, desejos e experiências, o emprego desses recursos tem como objetivo a instrumentalização de suas possibilidades comunicacionais, como apontam Efron, Fainberg, Kleiner, Sigal e Woscoboinik (2003).

A partir das entrevistas lúdicas com a criança pretendeu-se apreender:

- Fantasias e compreensão da criança a respeito da morte;

\section{WUV}

- O genitor sobrevivente ou um responsável pela criança assinou um Termo de Consentimento autorizando a participação da criança na pesquisa. A pesquisa foi realizada como exigência parcial para obtenção do título de Mestre por uma das autoras, não tendo sido exigido, à época, que passasse por Comitê de 
- Processo de luto da criança;

- Dinâmica familiar antes e após a morte.

Entrevista devolutiva: procedimento de desenhos-estória (D-E) ${ }^{5}$. Trata-se de uma técnica de investigação clínica da personalidade, de comprovada eficácia, que permite a apreensão de fantasias do sujeito. De acordo com Trinca (1983), autor do instrumento, o procedimento requer que o sujeito realize uma série de desenhos livres (cromáticos ou acromáticos), e conte uma estória associada livremente após a realização de cada desenho. Após o término de cada desenho acompanhado de estória, o examinador pode requerer esclarecimentos que permitam a compreensão do desenho-estória. Em seguida o examinador pede que o sujeito dê um título à estória. Sua aplicação é recomendada para crianças e adolescentes de cinco a quinze anos de idade (Trinca, 1997). Buscávamos apreender com sua utilização as fantasias da criança enlutada.

Seqüência de aplicação dos instrumentos na coleta de dados:

O procedimento de coleta de dados foi realizado da seguinte maneira: - entrevista com o genitor sobrevivente ou responsável; - entrevista familiar; - entrevista lúdica; -procedimento de desenhos-estória (D-E); - entrevista devolutiva com o genitor sobrevivente ou responsável.

As entrevistas e o procedimento de desenhos-estória (D-E) foram gravados em fitas de videocassete - com o consentimento da criança e de seus responsáveis - e transcritos em sua íntegra em seguida. Em um caso em que não houve autorização da criança para a gravação das entrevistas, elas foram transcritas em seguida.

\section{Procedimentos}

Foram realizadas análises das entrevistas e do procedimento de desenhos-estória. Em seguida foi feita uma análise integrada, com a utilização de todo o material disponível, compondo os estudos de caso. 0 material foi analisado de acordo com os padrões de interpretação de conteúdo propostos pela teoria psicanalítica.

A partir dos dados obtidos foram apreendidas as fantasias das crianças levando-se em conta os seguintes fatores:

- Momento de desenvolvimento psicossexual e cognitivo da criança;

- Condições circundantes ao evento da morte: tipo da morte; como aconteceu;

- Dinâmica familiar antes e após a morte:

- modo que a família lidou com a morte: informação fornecida e possibilidade de fazer perguntas; possibilidade de participar do luto familiar e espaço na família para o luto poder ser vivido;

- lugar determinado para a criança na família, antes e após a morte;

- relacionamento da criança com o genitor falecido e demais membros da família.

\section{Resultados}

O procedimento de coleta de dados foi realizado com cinco sujeitos (os nomes são fictícios, para preservar sua identidade) (Tabela 1):

As fantasias apreendidas foram as seguintes:

Duas das crianças do presente estudo, Beatriz e João Pedro, apresentaram, como fantasia principal (que delineia sua dinâmica emocional), a fantasia de identificação com o genitor morto de caráter predominantemente fusional, ou seja, de ocupar o lugar do

Tabela 1. Caracterização dos participantes.

\begin{tabular}{llll}
\hline Nome & Idade & Pessoa que morreu & Causa da morte \\
\hline João Pedro & 7 anos & pai & assassinato \\
Clara (irmã de & 3 anos & pai & assassinato \\
João Pedro) & & & AIDS \\
Eduardo & 7 anos & pai e mãe & acidente de moto \\
Beatriz & 8 anos & mãe & ataque cardíaco \\
Gabriela & 6 anos & mãe & \\
\hline
\end{tabular}

AIDS: Sindrome da imunodeficiência adquirida.

$\operatorname{cost}$

$\mathbf{5}$ Este instrumento foi utilizado com todas as crianças, exceto com Clara, em função de sua idade (três anos) ser inferior à idade mínima recomendada para sua aplicação. Por esse motivo foi realizada mais uma entrevista lúdica com ela. 
genitor morto. Os fatores que contribuíram à configuração dessa fantasia são: as crianças eram do mesmo sexo que o genitor falecido; fantasia inconsciente familiar de reposição da figura perdida; fantasia de identificação da família da criança com o genitor perdido. Essa fantasia apareceu associada ao impedimento da elaboração do luto (Tabela 2).

Em outras duas crianças, Clara e Gabriela, a fantasia de culpa edípica pela morte do genitor foi a predominante e os principais fatores que contribuíram para sua configuração foram: a relação ambivalente com o genitor perdido, o pensamento egocêntrico - típico do modo de pensamento pré-operatório - e o momento edípico de desenvolvimento psicossexual.

Para Eduardo, a fantasia principal foi de culpa pela destrutividade e os principais fatores que contribuíram para sua configuração foram: a relação ambi-

Tabela 2. Fantasias identificadas nos participantes.

\begin{tabular}{|c|c|}
\hline Fantasias & Conseqüências \\
\hline Aniquilamento & $\begin{array}{l}\text { Não poder agüentar o sofrimento } \\
\text { Não continência por parte do genitor sobre- } \\
\text { vivente/família } \\
\text { Vir a morrer }\end{array}$ \\
\hline Onipotência & $\begin{array}{l}\text { Evitar novas perdas e separações } \\
\text { Ser forte }\end{array}$ \\
\hline Culpa & $\begin{array}{l}\text { Ser culpado pela morte do genitor } \\
\text { Perder outra pessoa amada }\end{array}$ \\
\hline Castração & $\begin{array}{l}\text { Não poder se desenvolver } \\
\text { Estar destituído de valor e interesse }\end{array}$ \\
\hline Regressão & Voltar a ser bebê \\
\hline Reparatórias & $\begin{array}{l}\text { Encontrar ajuda para compreender o que } \\
\text { aconteceu Substituir o genitor morto } \\
\text { Poder entrar em contato com a dor } \\
\text { Recuperar o objeto perdido internamente }\end{array}$ \\
\hline Identificação & $\begin{array}{l}\text { Ser como o genitor falecido } \\
\text { Ocupar o lugar do genitor perdido }\end{array}$ \\
\hline Idealização & $\begin{array}{l}\text { O genitor sobrevivente é forte e potente } \\
\text { O genitor morto era forte e bom }\end{array}$ \\
\hline $\begin{array}{l}\text { Desidealização do } \\
\text { objeto perdido }\end{array}$ & $\begin{array}{l}\text { O genitor morto era frágil/mau } \\
\text { Atacar o genitor morto }\end{array}$ \\
\hline Negação da perda & $\begin{array}{l}\text { Recuperar o genitor morto } \\
\text { Não precisar do genitor morto }\end{array}$ \\
\hline Retaliação & Ser atacado pelo genitor morto \\
\hline Rejeição & Ter sido abandonado pelo objeto perdido \\
\hline Repetição & Reatualizar a situação da morte \\
\hline Agressiva & Vingar-se \\
\hline
\end{tabular}

valente e confusa com os genitores; medo da família, de sua agressividade e fantasia da família de identificação da criança com aspectos negativos dos pais; segredo em relação à causa da morte.

\section{Discussão}

O sentimento de desamparo parece ser aquele que predomina na mobilização das fantasias da criança, o que aponta para o fato de que a situação de morte de um ou ambos os pais gera, na criança, um sentimento de profunda ameaça em sua sobrevivência física e emocional. Isso se agrava pelo fato de que a criança, além de perder um dos genitores, perde também a situação familiar anterior, pois a família necessita reorganizar-se após a perda de um de seus membros. Além disso, o genitor sobrevivente ou responsável, em razão do vínculo com o falecido, está também muito mobilizado com a morte, o que acarreta uma dupla perda para a criança e uma sensação de maior desamparo.

A criança costuma sentir-se abandonada pela pessoa que morreu. Em função da grande idealização das figuras parentais, pode ser difícil para ela compreender que os pais sofreram algo, independentemente de sua vontade. A vivência de abandono é mais intensa quando a causa da morte do genitor vincula-se a uma atitude irresponsável ou de busca consciente ou inconsciente da morte.

Tendo em conta os casos estudados e a literatura a respeito (Bowlby, 1993; Winnicott, 1997; Worden, 1996), podemos levantar a hipótese de que a fantasia de ter sido responsável pela morte do genitor deve ser encontrada, em maior ou menor intensidade, em todas as crianças que perdem um genitor. Julgamos importante lembrar que, como aponta Grimberg (2000), o sentimento de culpa pode ser um componente importante para a elaboração, caso se trate de culpa depressiva, ou pode ser dificultador da mesma, no caso da culpa persecutória, sendo necessário atentar ao modo que a criança está vivenciando esse sentimento para que possamos compreender a função de determinada fantasia ligada à culpa, no processo de luto. Nos três casos em que a fantasia ligada à culpa era a predominante, ficou claro que a culpa persecutória estava dificultando os processos de elaboração. 
Segundo Klein (1970), se a ambivalência afetiva para com o objeto amado e perdido é muito intensa, tal objeto fica muito persecutório e é abalado o objeto interno protetor que confere segurança. A morte do objeto rival, no momento de elaboração edípica, intensifica as fantasias de culpa, de caráter persecutório, em relação aos desejos edípicos, o que dificulta a elaboração do Édipo e do luto. Quando a criança vive a situação edípica, a presença concreta do progenitor que é sentido como rival permite a constatação de que ainda que ela sinta raiva dele, não o destruiu; o objeto é suficientemente bom porque é capaz de suportar seus sentimentos de raiva, o que ameniza sua angústia e culpa. No entanto, quando o genitor objeto de rivalidade falece, a criança sente que seus desejos são muito poderosos e que seus sentimentos de raiva são muito destrutivos.

Pensamos que, nesse momento, é importante que alguém exerça o papel de continente para os sentimentos de raiva da criança, ajudando-a a lidar com a ambivalência emocional e seu sentimento de culpa. Porém, como pudemos perceber nos casos estudados, nesse momento, o genitor sobrevivente e os demais membros da família estão muito fragilizados e, muitas vezes, não conseguem oferecer o suporte de que a criança necessita. Nesse momento, a psicoterapia pode ser essencial como espaço de continência para a criança e sua família.

Julgamos importante ressaltar que o genitor sobrevivente deixe claro que, embora o lugar do genitor morto esteja vago, não é e não poderá ser da criança. Quando o genitor sobrevivente não o faz, atuando sentimentos contraedipianos em sua relação com a criança, esta pode ter seu sentimento de culpa incrementado, por sentir que triunfou perante o genitor morto e que suas fantasias edípicas podem ser concretizadas, aumentando a persecutoriedade do objeto perdido e dificultando a elaboração do luto.

O presente estudo aponta para o fato de que a agressividade reprimida em relação ao objeto perdido pode ser um entrave para a elaboração do luto. A dificuldade da criança em expressar sua agressividade aparece associada à pouca continência da família em relação aos sentimentos hostis da criança. A família não consegue ser continente para esses sentimentos quando não lida bem com a própria agressividade e culpa. Nesse caso, a criança e sua família necessitam utilizar defesas maníacas para não entrarem em contato com essa raiva, o que dificulta a elaboração do luto.

Percebemos que a situação de morte violenta é um fator determinante de fantasias, sentimentos e reações comportamentais específicos. Assim, por exemplo, a desidealização brusca do genitor perdido, as dificuldades de identificação com esse progenitor e o intenso sentimento de desamparo e fragilidade diante da vida apareceram associados à perda do genitor por morte violenta.

A compreensão da dinâmica do caso e do eixo principal que determina a configuração das fantasias da criança permite-nos compreender como a criança elabora a perda e os fatores que podem dificultar esse processo, indicando a intervenção apropriada, quando necessário.

Embora possamos encontrar fantasias semeIhantes em diferentes crianças, o que pareceria uniformizar seu universo fantasmático, há determinados fatores cujo interjogo confere o colorido das fantasias, tornando-as únicas para cada criança. A variabilidade da construção das fantasias de crianças que passaram pela experiência de morte de um ou ambos os pais parece dar-se de acordo com os seguintes fatores:

- Momento de desenvolvimento da criança: psicossexual, cognitivo e modo de funcionamento egóico;

- Condições circundantes ao evento da morte: tipo da morte; como aconteceu;

- Dinâmica familiar antes e após a morte:

- Modo como a família lidou com a morte: informação fornecida e possibilidade de fazer perguntas; possibilidade de participar do luto familiar, espaço na família para o luto poder ser vivido;

- lugar determinado para a criança na família, antes e após a morte;

- relacionamento da criança com o genitor falecido e demais membros da família.

Pudemos chegar ao apontamento de alguns fatores que poderiam facilitar e outros que poderiam dificultar a elaboração do luto da criança.

- Fatores dificultadores: 
A) Família: não fornecimento de informação correta a respeito da morte do genitor; atitude de negação do sofrimento por parte da família; não compartilhar o luto com a criança; exigência consciente/ inconsciente de que a criança ocupe o lugar do genitor perdido; continência insuficiente para os sentimentos de desamparo e abandono da criança; relação muito ambivalente com o membro perdido; distanciamento afetivo do genitor sobrevivente na família.

B) Criança: relação com o genitor perdido: muito ambivalente; confusa e indefinida; ser do mesmo sexo que o genitor; relação de apego ansioso.

Momento de desenvolvimento cognitivo: momento de desenvolvimento cognitivo pré-operatório.

Momento de desenvolvimento emocional da criança: criança que não elaborou bem a posição depressiva; modo de funcionamento egóico predominantemente na posição esquizoparanóide; momento de elaboração do Édipo.

C) Circunstâncias da morte: repentina; violenta; prematura; testemunho da criança na situação da morte violenta; segredo a respeito da causa da morte; morte tratada na família como tabu; situação de morte em que houve descuido real por parte do genitor; desejo consciente/inconsciente de morte por parte do genitor.

- Fatores facilitadores: possibilidade de expressão dos sentimentos (na família e/ou em situação psicoterápica) e modo de funcionamento egóico da criança e da família predominantemente na posição depressiva.

Levantamos a hipótese de que há fantasias que refletem processos elaborativos do luto, enquanto outras estão associadas à complicação da elaboração. É importante esclarecer que a presença dessas fantasias pode ser um indicativo para o diagnóstico do luto da criança, não tendo a pretensão de encerrar uma avaliação. As fantasias estavam associadas a processos elaborativos quando relacionadas a um funcionamento egóico predominantemente na posição depressiva e associavam-se a complicações no processo quando o mecanismo predominante era esquizoparanóide.

Fantasias que podem estar associadas à complicação na elaboração: fantasias de culpa de caráter persecutório (ser culpado pela morte do genitor; perder outra pessoa amada); fantasias de retaliação do objeto perdido (ser atacado pelo genitor morto); fantasias de aniquilamento (não poder agüentar o sofrimento; não continência por parte do genitor sobrevivente/ família; vir a morrer); fantasias de identificação, de caráter fusional, com o objeto perdido e de identificação com aspectos considerados - pela criança e/ou pela família - negativos do genitor (ser como o genitor; ocupar o lugar do genitor); fantasias de castração (não poder se desenvolver; estar destituído de valor e interesse); fantasias de rejeição (ter sido abandonado pelo genitor); fantasias de desidealização do objeto perdido, quando a desidealização se dá de modo brusco (o genitor morto era frágil/mau; atacar o genitor morto).

Fantasias que refletem processos elaborativos do luto: fantasias reparatórias (substituir o genitor morto; recuperar o genitor morto internamente; encontrar ajuda para compreender o que aconteceu); fantasias de identificação com aspectos considerados - pela criança e/ou pela família - positivos do genitor (ser como o genitor); fantasias de repetição da situação da perda (reatualizar a situação da morte); fantasias de desidealização do objeto perdido quando a desidealização se dá de modo gradual (o genitor morto era frágil/mau; atacar o genitor morto).

Percebemos, ainda, a existência de um terceiro grupo de fantasias que parecem ter a função de defesa, talvez necessária em um primeiro momento de elaboração do luto e, dessa forma, importante para que ocorra a elaboração em um segundo momento. Ao mesmo tempo, se a defesa prolonga-se indefinidamente, a perda não pode ser elaborada. Portanto essas fantasias em si não podem ser consideradas como indicativas de processos elaborativos ou complicadores da elaboração. Pensamos que sua intensidade e o tempo que atuam no mundo fantasmático da criança são os fatores que indicarão a função que estão exercendo prioritariamente. Essas fantasias são: fantasias de onipotência (evitar novas perdas e separações; ser forte); fantasias de negação da perda (sentimento de não precisar do genitor perdido); fantasias de idealização; fantasias regressivas.

\section{Considerações Finais}

As fantasias refletem o processo de elaboração do luto da criança em decorrência da morte de um ou 
ambos os genitores e seu conhecimento possibilita a compreensão de seus sentimentos, comportamentos e sintomas. A partir da apreensão de suas fantasias e de seu processo de enlutamento, é possível auxiliá-la a compreender o que vivencia, contribuindo para seu processo de elaboração da perda.

A aproximação de seu mundo fantasmático, daquilo que acontece com ela não apenas no plano consciente, mas também no nível inconsciente, pode oferecer instrumentos para o profissional que trabalha com o luto infantil. Com o levantamento de suas fantasias, dos fatores internos e externos a elas associados, pretendemos contribuir para tal instrumentalização. Essa compreensão parece-nos importante tanto para o psicoterapeuta que atende crianças e sua família, como para os demais profissionais que lidam com a criança e para os próprios pais ou responsáveis. Encontrando um ambiente mais preparado para recebê-la, a criança pode sentir-se acolhida, compreendida e mais segura em um momento de tanta insegurança e desamparo.

Nosso estudo apontou, ainda, para a necessidade de atentarmos à família sempre que uma criança enlutada é trazida para atendimento psicoterápico. Notamos que a possibilidade de a criança elaborar o luto vincula-se ao processo de elaboração do luto pela família e à fantasmática inconsciente familiar. A criança está inserida em um sistema familiar que vive um momento de crise e desorganização. Portanto trabalhar somente com a criança, especialmente em um primeiro momento da intervenção, não parece ser tão eficiente quanto realizar intervenções também com a família.

\section{Referências}

Arzeno, M. E. G. (2003). A entrevista familiar diagnóstica. Importância da sua inclusão no psicodiagnóstico de crianças. In Psicodiagnóstico clínico: novas contribuições. Porto Alegre: Artes Médicas.

Aberastury, A. (1992). Psicanálise da criança: teoria e técnica. Porto Alegre: Artes Médicas.

Beckman, R. (1990). Children who grieve. Holmes Beach: Learning Publications.

Bowlby, J. (1960). Grief and mourning in infancy and early childhood. Psychoanal Study Child, 15, 9-52.

Bowlby, J. (1979). Formação e rompimento dos laços afetivos. São Paulo: Martins Fontes.

Bowlby, J. (1993). Perda: tristeza e depressão. In Apego e perda (Vol.3). São Paulo: Martins Fontes.
Domingos, B., \& Maluf, M. R. (2003). Experiências de perda e luto em escolares de 13 a 18 anos. Psicologia Reflexão e Crítica, 16 (3), 577-589.

Freud, S., \& Breuer, J. (1893-1895 [1996]). Estudos sobre a histeria. In Obras completas. Rio de Janeiro: Imago.

Freud, S. (1917 [1915]) [1996]). Luto e melancolia. In Obras completas. Rio de Janeiro: Imago.

Grimberg, L. (2000). Culpa e depressão. Lisboa: Climepsi.

Guérin, G. (1979). Estar de luto. In A criança e a morte: crianças doentes falam da morte: problemas da clínica do luto. Rio de Janeiro: Francisco Alves.

Klein, M. (1970). Contribuições à psicanálise. São Paulo: Mestre Jou.

Klein, M. (1996a). O luto e suas relações com os estados maníaco-depressivos. In Amor, culpa e reparação e outros trabalhos. Rio de Janeiro: Imago.

Klein, M. (1996b). O desmame. In Amor, culpa e reparação e outros trabalhos. Rio de Janeiro: Imago.

Kraus, F., \& Monroe, B. (2005). Briefinterventions with bereaved children. Oxford: Oxford University Press.

Laplanche, J., \& Pontalis, J-B. (2000). Vocabulário de Psicanálise. São Paulo: Martins Fontes.

Mazorra, L. (1997). Fantasias de crianças enlutadas: um estudo de caso. Trabalho de Conclusão de Curso de Psicologia não-publicada, Pontifícia Universidade Católica de São Paulo.

Scalozub, L. T. (1998). El duelo y la niñez. Mas allá de las fronteras del Psicoanálisis. Revista de la Asociación de Buenos Aires: abordages en Psicoanálisis de Niño, 20, 367-83.

Sekaer, C. (1987). Towards a definition of "childhood mourning". American Journal of Psychotherapy, 41 (2), 201-219.

Torres, W. (1996). A criança diante da morte. Arquivos Brasileiros de Psicologia, 48, 31-41.

Torres, W. (1999). A criança diante da morte: desafios, São Paulo: Casa do Psicólogo.

Trinca, W. (1983). O pensamento clínico em diagnóstico da personalidade. Petrópolis: Vozes.

Trinca, W. (1997). Visão geral e atualidade dos procedimentos: apresentação e aplicação. In Formas de investigação clínica em psicologia. São Paulo: Vetor.

Winnicott, D. W. (2000). A preocupação materna primária. In Da pediatria à psicanálise: obras escolhidas. Rio de Janeiro: Imago.

Worden, J. W. (1996). Children and grief. When a parent dies. New York: Guilford Press.

Worden, J. W. (1998). Luto e sistemas familiares. In Terapia do luto. Porto Alegre: Artes Médicas.

Recebido em: 20/8/2006

Versão final reapresentada em: 3/4/2007

Aprovado em: 25/4/2007 
